\title{
Bevacizumab and Sorafenib Modulate P-Glycoprotein Function In Vitro and Bevacizumab Increases In Vivo Sorafenib Plasma Concentrations in Mice
}

\author{
Mahamadou Tandia ${ }^{\text {ad }}$, Chadi Abbara ${ }^{\text {ab }}$, Marie-Sophie Noel-Hudson ${ }^{a}$, Dora Amor ${ }^{\text {a }}$, Mélanie Polrot ${ }^{c}$, Patrick \\ Gonin $^{\mathrm{c}}$, Laurence Bonhomme-Faivre ${ }^{\text {ad }}$ \\ ${ }^{a}$ Laboratory of Pharmacology, Service Pharmacie, Hôpital Paul Brousse AP-HP, 14 avenue Paul-Vaillant Couturier, \\ 94800 Villejuif, France \\ ${ }^{\mathrm{b}}$ Department of Pharmacology and Toxicology, Centre Hospitalier Universitaire d'Angers, 4 rue Larrey, \\ 49100 Angers, France \\ ${ }^{c}$ Animal and Veterinary Resources, IFR 54, Institut Gustave Roussy, 39 rue Camille Desmoulins, 94800 Villejuif, France \\ ${ }^{d}$ UMR 935- Inserm Modèles Des Cellules Souches Malignes et Thérapeutiques, Institut André Lwoff, 94800 Villejuif, \\ France
}

*Correspondence author: mahamadou.tandia@aphp.fr

Received 26 May 2020;

Accepted 07 July 2020;

Published 01 August 2020

\begin{abstract}
Overexpression of P-glycoprotein (P-gp) is associated with multidrug resistance. Since sorafenib (NEXAVARß) is a P-gp (an efflux protein of ATP-binding cassette family) substrate, we tested whether bevacizumab (AVASTIN®), a monoclonal antibody directed toward VEGF (Vascular Endothelial Growth Factor) and sorafenib could modulate P-gp functionality.

In vitro two human ovarian carcinoma cells (IGROV1) overexpressing or weakly expressing P-gp were used. Bevacizumab and sorafenib effects on P-gp functionality were evaluated by measuring doxorubicin intracellular accumulation.

In vivo study was to document whether bevacizumab could modify sorafenib disposition in mice. Therefore, concentrations of sorafenib were determined by HPLC in plasma of mice bearing a human colorectal carcinoma xenograft when sorafenib is given orally ( $5 \mathrm{mg} / \mathrm{kg}$ ) on day 4, alone or after a pretreatment with bevacizumab ( $5 \mathrm{mg} / \mathrm{kg} \mathrm{IP})$ on days 1 and 3.

In vitro a significant doxorubicin accumulation and reversion of doxorubicin resistance in P-gp expressing cell lines were observed with bevacizumab or sorafenib pretreatment

In vivo, sorafenib AUC was 1.44 fold significantly higher in bevacizumab pretreated group and Cmax was 1.35 fold higher in bevacizumab-pretreated group. Mean residence time of sorafenib increased in the presence of bevacizumab, this increase reflects an improvement of sorafenib bioavailability after bevacizumab pretreatment.

We may conclude that bevacizumab pretreatment decreases P-gp functionality and increases doxorubicin intracellular accumulation in vitro and sorafenib plasma concentrations in vivo.
\end{abstract}

Keywords: Sorafenib, bevacizumab, P-glycoprotein, pharmacokinetics, ABCB1

\section{Introduction}

Sorafenib (NEXAVAR $\left.{ }^{\circledR}\right)$ is an oral multitarget tyrosine kinase inhibitor (CRAF, BRAF, V600E BRAF, FLT3, and C-KIT); it also inhibits tumor vasculature (CRAF, VEGF-R1, R2 and R3, PDGFR b). It is indicated in the treatment of advanced HCC, advanced renal cell carcinoma after failure of previous treatment with interferon alfa or interleukin-2 in patients in whom these therapies were inadequate ${ }^{[1,2,3]}$. It is indicated also in the treatment of progressive, locally advanced or metastatic differentiated thyroid carcinoma.

However sorafenib is a drug with a high inter and intraindividual pharmacokinetic variability ${ }^{[4,5,6]}$. It is the substrate of efflux transporters, breast cancer resistance Protein (BCRP) and Pglycoprotein $(\mathrm{ABCB} 1)^{[7]}$, with a potential risk of under exposure of patients treated with this drug. Sorafenib-resistant cells showed increased metastatic and invasive ability, with a higher expression of P-glycoprotein (P-gp), compared to that of the parental cells ${ }^{[8]}$. 
M. R. Bani et al ${ }^{[9]}$ showed that tumor endothelial cells (TEC) may acquire drug resistance, a characteristic that is maintained in vitro. There is evidence that TEC are more resistant to chemotherapeutic drugs, substrates of ATP-binding cassette $(\mathrm{ABC})$ transporters. TEC express P-glycoprotein (encoded by $\mathrm{ABCB} 1$ ), while no difference with other $\mathrm{ABC}$ transporters was revealed compared to normal endothelia. In intratumor vessels, they might contribute to create a "bloodtumor barrier", interfering with the delivery of chemotherapy to neoplastic cells. TEC show reduced sensitivity to some chemotherapeutic drugs compared to normal endothelial cells. Increasing evidence suggests that TEC are the first line of tumor chimioresistance.

Inhibition of VEGF biological activity by bevacizumab, a humanized monoclonal antibody (immunoglobulin G 1) could improve the activity of a co-administrated chemotherapy ${ }^{[10]}$.

The use of bevacizumab to patients with metastasic colorectal cancer (mCRC) provides progression-free survival (PFS) and overall survival (OS) advantages when combined with cytotoxic chemotherapy in the first and second line settings ${ }^{[11]}$.

In recurrent glioblastoma patient the combination of bevacizumab with sorafenib has resulted in high objective response rate $^{[12]}$.

Since sorafenib is a multikinase inhibitor targeting several serine/threonine and tyrosine kinases and including all VEGFreceptors, Raf, PDGF receptor B, and FGF receptor 1, the J.M. Hubbard et al have shown that dual antiangiogenic treatment combined with cytotoxic therapy may provide prolonged disease stabilization for select patients with advanced GI malignancies ${ }^{[13]}$.

Philippe V. et al have studied the clinical influence of sorafenib and bevacizumab on pancreatic cancer volume and have shown that pancreatic volume decreases statistically significantly under treatment with both the multi-tyrosine kinase inhibitor sorafenib and the angiogenesis inhibitor bevacizumab ${ }^{[14]}$.

Several other clinical trials have focused on the combination of sorafenib and bevacizumab in the treatment of patients with metastatic colorectal cancer ${ }^{[15]}$

Since sorafenib is a multikinase inhibitor targeting several serine/threonine and tyrosine kinases and including all VEGFreceptors, Raf, PDGF receptor $\mathrm{B}$, and FGF receptor 1, the combinaison of bevacizumab and sorafenib might provide a more complete blockade of proangiogenic pathways as well as inhibit mechanisms of bevacizumab resistance like surexpression of P-gp in endothelial cells

In the present work we studied potential interactions between anti-angiogenic drugs (sorafenib, and bevacizumab) and P-gp functionality. We studied the effect of sorafenib and /or bevacizumab on doxorubicin resistant cells (IGROV1-DXR) over expressing P-gp.

In vivo we studied how pretreatment with bevacizumab of human colorectal carcinoma bearing mice modifies plasma sorafenib concentrations.

\section{Material and Methods}

\subsection{Drugs}

Doxorubicin was purchased from Teva (Paris France), verapamil from Abbott (Paris France) bevacizumab (AVASTIN ${ }^{\circledR}$ ) $[25 \mathrm{mg} / \mathrm{mL}]$ were purchased from Pfizer (Montrouge, France) and Roche Registration Limited (Welwyn Garden City, United Kingdom) laboratories, respectively.

\subsection{Chemicals}

Sorafenib $\left(\right.$ Nexavar $\left.^{\circledR}\right)$ was purchased from Bayer Pharma ${ }^{\circledR}$ (Berlin, Germany), erlotinib (internal standard, IS) was purchased from LC® laboratories (Woburn, USA). Dullbecco's modified Eagle's medium (DMEM), fotal calf serum (FCS), phosphate-buffered saline (PBS), penicillin, streptomycin, zeocin, hygromycin B. were purchased from Gibco Invitrogen (Cergy-Pontoise France). Acetonitrile and methanol (liquid-chromatography grade), tetrabutyl ammonium and trifluoroacetic acid were purchased from Sigma-Aldrich Corporation (St. Louis, MO, USA), Acetic Acid were purchased from VWR BDH Prolabo (Haasrode, Belgium), 3(4,5-dimethylthiazol-2-yl)-2,5-diphenyltetrazoliumbromide (MTT) assay (Sigma-Aldrich Chemical Co, Saint-Quentin, France) ethyl acetate, acetonitrile and dimethylsulfoxide (DMSO) from VWR® (Fontenay-sous-Bois, France). Ammonium acetate was purchased from Sigma ${ }^{\circledR}$ (St. Louis, MO, USA). Deionized purified water was prepared in our laboratory using DirectQ UV® System (Millipore SAS®, Molsheim, France).

\subsection{Cell lines}

The IGROV1 cells were obtained from Dr. Bernard (Bernard et al., 1985) at the CNRS 8126 laboratory in Villejuif, France.

\subsubsection{Establishment of sensitive and resistant doxorubicin cell lines: IGROV1-p and IGROV1-DXR}

A doxorubicin-resistant cell line (IGROV1-DXR), which overexpressed P-gp, was derived from the parental drug-sensitive cell line (IGROV1-p). IGROV1-p cell line was derived from a stage III human ovarian carcinoma. The characterization of the parental sensitive IGROV1-p has been reported previously ${ }^{[16,17]}$. The IGROV1-DXR cells were selected from IGROV1-p cells by continuous exposure of these cells to increasing concentrations of doxorubicin in a gradual step-wise manner, up to $0.1 \mu \mathrm{g} / \mathrm{ml}$ for doxorubicin. Cell lines were grown as adherent monolayers supplemented with $10 \%(\mathrm{v} / \mathrm{v}) \mathrm{FCS}$, penicillin $(100 \mathrm{U} / \mathrm{ml})$ and streptomycin $(100 \mu \mathrm{g} / \mathrm{ml})$ at $37^{\circ} \mathrm{C}$ in a humidified atmosphere of $5 \% \mathrm{CO} 2$ in air. IGROV1-DXR cells were maintained in medium supplemented with doxorubicin $(0.1 \mu \mathrm{g} / \mathrm{ml})$.

2.3.2.. Doxorubicin accumulation assay measured by flow cytometric analysis FACS

P-gp function assessment.

Cell-based doxorubicin transport assays were performed in IGROV1-p and IGROV1-DXR cell lines. Cells were incubated in DMEM with doxorubicin alone $(10 \mu \mathrm{M})$ plus 5\% FBS during $2 \mathrm{~h}$ at $37{ }^{\circ} \mathrm{C}$ in order to compare doxorubicin accumulation in the two cell lines. After incubation with doxorubicin, cells were washed twice with PBS and dissociated with $0.05 \%$ Trypsin-EDTA buffer. Cells were re-suspended in DMEM plus 10\% FCS then centrifuged. After washing three times with PBS to eliminate extracellular doxorubicin, fluorescence due to doxorubicin intracellular accumulation was measured by flow cytometer analysis (acquisition of data for 10,000 cells in channel 2)

\subsubsection{Effect of bevacizumab on P-gp function in IGROV1-DXR lines.}

Effect of bevacizumab was tested at 2 different concentrations (1 $\mathrm{mg} / \mathrm{ml}$ and $5 \mathrm{mg} / \mathrm{ml}$ ) co-incubated in DMEM with doxorubicin 10 $\mu \mathrm{M}$ and $5 \% \mathrm{FCS}$ during $2 \mathrm{~h}$ at $37^{\circ} \mathrm{C}$. Bevacizumab effect was also tested on IGROV1-p cells. Verapamil was used during doxorubicin incubation as a positive control. P-gp function assessed by doxorubicin accumulation was expressed as percentage of doxorubicin accumulation through the following equation: 
100 x (MFI bevacizumab - MFI control)/MFI control.

\subsubsection{Effect of sorafenib on P-gp function in IGROV1-DXR} lines.

Effect of sorafenib was tested at 2 different concentrations (5 $\mathrm{mg} / \mathrm{ml}$ and $10 \mathrm{mg} / \mathrm{ml}$ ) co-incubated in DMEM with doxorubicin 10 $\mu \mathrm{M}$ and $5 \%$ FCS during $2 \mathrm{~h}$ at $37^{\circ} \mathrm{C}$. Sorafenib effect was also tested on IGROV1-p cells. Verapamil was used during doxorubicin incubation as a positive control. P-gp function assessed by doxorubicin accumulation was expressed as percentage of doxorubicin accumulation through the following equation:

100 x (MFI sorafenib - MFI control)/MFI control.

\subsection{Human colorectal carcinoma bearing mice}

In this study, was used a xenograft model originating from a human tumour collection, established under the CReMEC projet: the CRIGR016P primary xenograft. The patient, from whom the tumour originated, was a woman, with an adenocarcinoma of the sigmoid colon with ovarian metastases. The sample was directly derived from the primary tumour.

The CR-IGRO16P tissue was cut into small pieces. These tissues were subcutaneously implanted into Female Foxn1nu CD-1 nude mice flanks. These mice were purchased from Animal and Veterinary Resources, Institut Gustave Roussy, IFR54 (Villejuif, France). Mice were housed under standard laboratory sterile conditions, with sterile water and regular sterile (gamma-irradiated) chow provided ad libitum in a 12-h/12-h light/dark cycle at a 21$23^{\circ} \mathrm{C}$ temperature. Anesthesia was induced with $5 \%$ isoflurane and maintained with $2.5 \%$ isoflurane in air. When the tumour had reached $2-3 \mathrm{~cm}$ in diameter, it was sampled and cut into small pieces to obtain the second-passage model, which was used in the study.

\subsection{Sorafenib pharmacokinetic studies}

Six weeks old male nude mice (20-30 g) were purchased from Animal and Veterinary Resources of Gustave Roussy Institut (IGR Villejuif, France). Mice were randomized into two groups of 21 mice each. The first group received orally sorafenib at the dose of 5 $\mathrm{mg} / \mathrm{kg}$. The second group was pre-treated intraperitoneally with bevacizumab at the dose of $5 \mathrm{mg} / \mathrm{kg}$ on days 1 and 3 and one hour later received orally sorafenib at $5 \mathrm{mg} / \mathrm{kg}$.

Three mice randomly chosen were anaesthetized with isoflurane and sacrificed by cervical dislocation, their blood was collected by cardiac puncture in heparinized tubes at $0.5,1,2,3,6$ and $16 \mathrm{~h}$ after sorafenib administration. After centrifugation at $3,000 \mathrm{rpm}$ for 5 minutes at $4^{\circ} \mathrm{C}$, plasma was transferred to propylene tubes and stored at $-20^{\circ} \mathrm{C}$ until assays.

The animals were treated in accordance with the European Committee standards concerning the care and use of laboratory animals. The experimental protocol was approved by Local Animal Experimentation Committee $\left(\mathrm{N}^{\circ} 26\right.$, Ministère de la Recherche et de l'Enseignement Supérieur).

\subsection{Sorafenib quantification in plasma}

Sorafenib concentrations were measured by a HPLC method coupled with UV-visible detector validated according to the recommendations for bioanalytical method validation ${ }^{[21]}$.

We used Shimadzu ${ }^{\circledR}$ chromatography system with UV detector and Labsolutions ${ }^{\circledR}$ chromatography workstation (Shimadzu Corporation ${ }^{\circledR}, \quad$ Kyoto, Japan). Chromatographic separation was achieved on a C18 ultrasphere ODS $®$ column $(250$ $\mathrm{mm}$ x $4.6 \mathrm{~mm}, 5 \mu \mathrm{m}$; Phenomenex ${ }^{\circledR}$, Pecq, France) associated with a guard column packed with the same phase.
The calibration was linear in the range of $50-700 \mathrm{ng} / \mathrm{mL}$. The accuracy, within-assay and between-assay precision of the method was $96.9-104.0 \%, 3.4-6.2 \%$ and $7.6-9.9 \%$, respectively. Three sorafenib quality controls were prepared in drug-free plasma: low (50 ng/mL), medium (300 ng/mL) and high (500 ng/mL). The composition of the mobile phase was $40 \%$ ammonium acetate $(20$ $\mathrm{mM}$ ) and $60 \%$ acetonitrile, delivered at a flow rate of $1.2 \mathrm{~mL} / \mathrm{min}$.

\subsection{Data analysis}

Data were analysed separately for each mouse group, average concentration at each sampling time was used. A noncompartmental analysis was performed using WINNONLINE professional version 5.2 software (Pharsight, Mountain View, CA, USA). The mean maximum concentrations (Cmax) and the times necessary to reach it (Tmax) were evaluated from experimental curves. Terminal half-lives ( $\mathrm{t} 1 / 2)$ were calculated from the respective terminal rate constants $(\mathrm{Ke})$, estimated as the slope of the log-linear terminal portion of the mean concentration vs time curve, by linear regression analysis. The mean areas under the concentration-time curves (AUC) were calculated by the trapezoidal method from 0 to the last concentration-time point. AUC of the two groups were compared using Bailer's method ${ }^{[18]}$.

Statistical significance was set at $p<0.05$. Results are expressed as mean \pm standard error to mean (SEM). Under the null hypothesis which indicates that mean AUC are equal, this statistics follows a normal distribution. The null hypothesis is rejected if $\left|Z_{\text {obs }}\right|$ is greater than 1.96 .

\section{Results}

\subsection{In vitro study}

\subsubsection{Effect of sorafenib on doxorubicin intracellular accumulation}

Decrease of P-gp activity by sorafenib was measured by the amount of doxorubicin intracellular accumulation in IGROV1-p and IGROV1-DXR when cultured in presence of sorafenib. Significant dose-dependent increase of doxorubicin uptake in IGROV1- DXR cells was observed when sorafenib was added to the culture at concentrations of $5.0 \mu \mathrm{M}\left({ }^{*} P<0.05 ; \mathrm{n}=3\right)$ and 10.0 $\mu \mathrm{M}(* * P<0.01 ; \mathrm{n}=3)$ as compared to IGROV1-DXR cells not treated with sorafenib (control cells). In IGROV1-p cells, a non statiscally significant increase of doxorubicin uptake by cells was observed with sorafenib at the concentration of $10.0 \mathrm{mg} / \mathrm{ml}$ as compared to control cells. Treatment by the P-gp inhibitor, verapamil, at $10 \mu \mathrm{M}$ led to a significant increase in doxorubicin uptake in IGROV1-DXR cells as compared to control cells $(* * P<0.01 ; \mathrm{n}=3)$ (table 1, figure 1$)$.

\subsubsection{Effect of bevacizumab on doxorubicin intracellular} accumulation

The modification of P-gp activity by bevacizumab in vitro was measured by the intensity of doxorubicin intracellular accumulation in IGROV1-p and IGROV1-DXR when cultured in presence of bevacizumab. Significant dose-dependent increase of doxorubicin uptake in IGROV1- DXR cells was observed when they are incubated with bevacizumab at concentrations of $1.0 \mu \mathrm{M}$ $(* * P<0.01 ; \mathrm{n}=3)$ and $5.0 \mu \mathrm{M}(* * P<0.01 ; \mathrm{n}=3)$ as compared to IGROV1-DXR cells no treated with bevacizumab control cells. In IGROV1-p cells, a non statiscally significant increase of doxorubicin uptake by cells was observed with bevacizumab as compared to control cells. Treatment by the P-gp inhibitor, verapamil, at $10 \mu \mathrm{M}$ led to a significant increase in doxorubicin uptake in IGROV1-DXR cells as compared to control cells $(* * * P<0.01 ; \mathrm{n}=3)$ (table 2, figure 2$)$. 
International Journal of Innovative Research in Medical Science (IJIRMS)

Volume 05, Issue 08, August 2020,

https://doi.org/10.23958/ijirms/vol05-i08/396

Table 1: Sorafenib pretreatment effect on doxorubicin intracellular accumulation in parental or doxorubicin resistant IGROV1 cells

\begin{tabular}{|l|l|l|l|l|}
\hline Doxorubicin concentration $\boldsymbol{\mu M}(\mathbf{M e a n} \pm \mathbf{S D})$ & control & Sorafenib 5 $\boldsymbol{\mu M}$ & Sorafenib 10 $\boldsymbol{\mu M}$ & verapamil 10 $\boldsymbol{\mu M}$ \\
\hline IGROV1-DXR & $99 \pm 3$ & $204 \pm 3^{*}$ & $336 \pm 18^{* *}$ & $329 \pm 49^{* *}$ \\
\hline IGROV1-P & $780 \pm 14$ & $738 \pm 14$ & $827 \pm 21$ & $604 \pm 41$ \\
\hline
\end{tabular}

$* p<0.05 ; * * p<0.01$

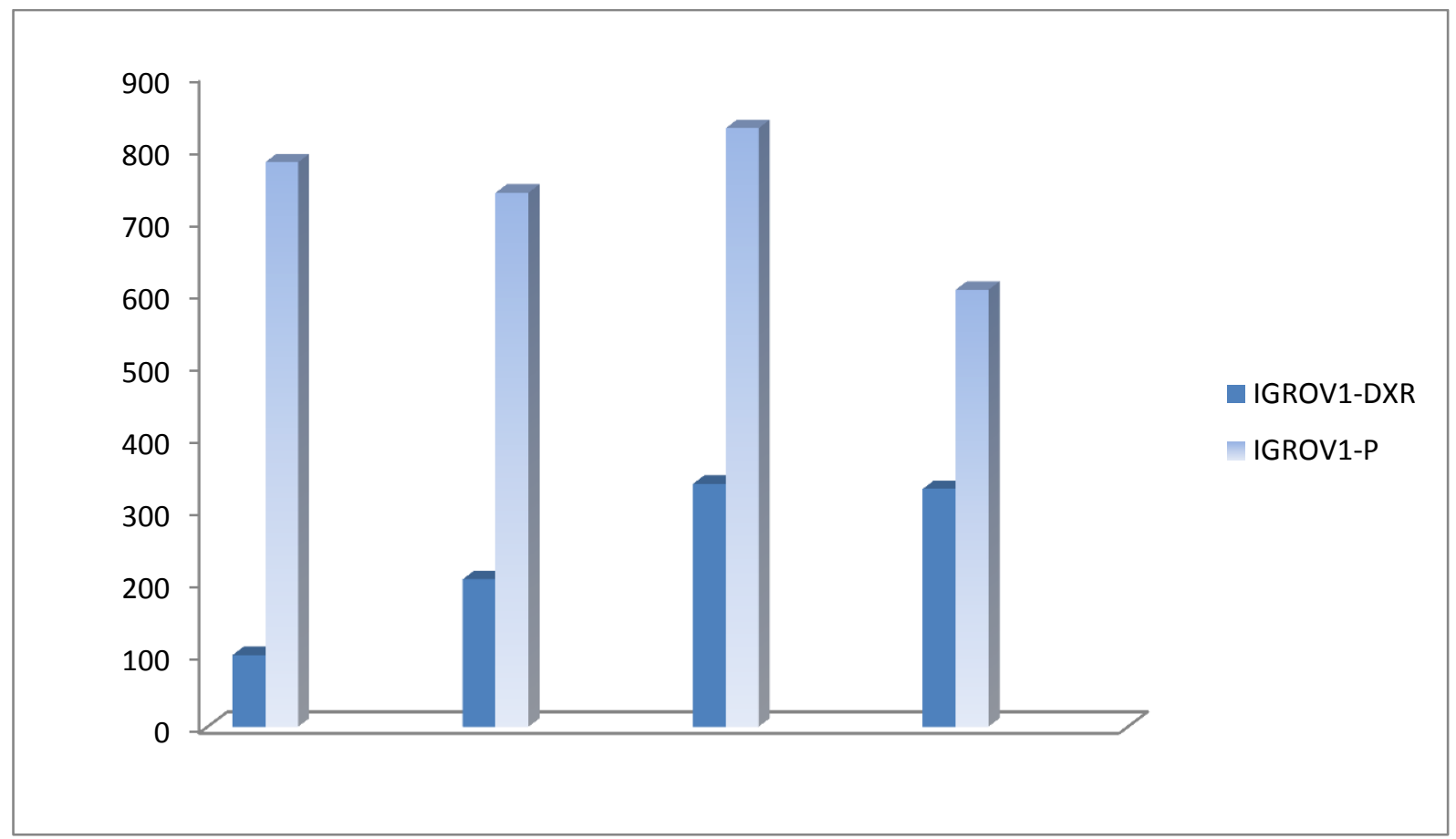

$* p<0.05 ; * * p<0.01$

Figure 1: Doxorubicin intracellular accumulation in IGROV1- DXR and IGROV1-P cells after preteatement with sorafenib (n=3)

Table 2: Bevacizumab pretreatment effect on doxorubicin intracellular accumulation in IGROV1 parental or doxorubicin resistant cells

\begin{tabular}{|c|c|c|c|c|}
\hline Doxorubicin concentration $\mu \mathrm{M}(\mathrm{Mean} \pm \mathrm{SD})$ & control & Bevacizumab $1 \mu \mathrm{M}$ & Bevacizumab 5 $\mu \mathrm{M}$ & Verapamil $10 \mu \mathrm{M}$ \\
\hline IGROV1-DXR & $357 \pm 7$ & $890 \pm 74 * *$ & $1283 \pm 24 * *$ & $1432 \pm 19 * *$ \\
\hline IGROV1-P & $1933 \pm 62$ & $2054 \pm 35$ & $1900 \pm 37$ & $2399 \pm 89$ \\
\hline
\end{tabular}

$* * p<0.01$

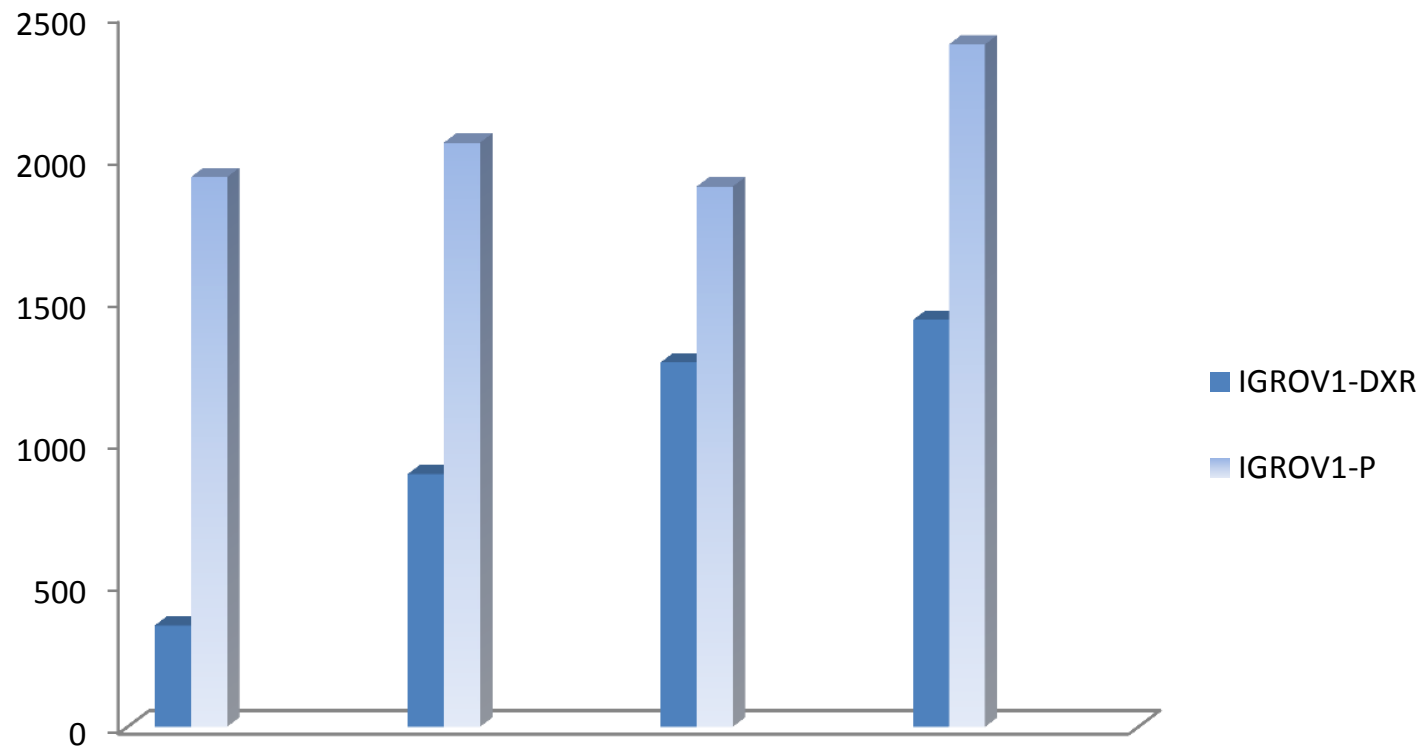


$* p<0.05 ; * * p<0.01$

Figure 2: Doxorubicin intracellular accumulation in IGROV1- DXR and IGROV1-P cells after preteatement with bevacizumab (n=3)

3.2. Effect of bevacizumab pretreatement on plasma pharmacokinetic parameters of sorafenib in mice bearing human colorectal carcinoma xenograft

The mean plasma concentrations of sorafenib are reported in table 3 and figure 3 , they represent the sorafenib plasma concentrations versus time curves. Using a noncompartmental analysis, plasma pharmacokinetic parameters of sorafenib were calculated (table II). In both non pretreated and bevacizumab pretreated groups, Tmax was observed 3 hours after sorafenib administration, bevacizumab pretreatment does not affect the time required to reach the maximal plasma concentration of sorafenib. Sorafenib AUC was 1.44-fold higher in bevacizumab-treated group (Zobs $=2.86>\mathrm{Z}$ table), this difference was statistically significant. Cmax was 1.35 - fold higher in bevacizumab-pretreated mice group, but this increase was not statistically significant. Half-life and MRT were respectively 2.91and 2.71 - fold higher in pretreated group.

Table 3: Plasma pharmacokinetic parameters of sorafenib after oral administration $(5 \mathrm{mg} / \mathrm{kg})$ in nude mice bearing human colorectal carcinoma and which received or not bevacizumab $(5 \mathrm{mg} / \mathrm{kg})$. A noncompartimental analysis.

\begin{tabular}{|l|l|l|l|}
\hline & $\begin{array}{l}\text { Mice that received only } \\
\text { sorafenib }\end{array}$ & $\begin{array}{l}\text { Mice that received sorafenib after } \\
\text { bevacizumab pretreatment }\end{array}$ & Probability \\
\hline Cmax $(\mathrm{ng} / \mathrm{ml})$ & $273.91 \pm 55.19$ & $370.56 \pm 104.75$ & $\mathrm{p}=0.23(\mathrm{NS})$ \\
\hline AUC $0-16 \mathrm{~h}(\mathrm{~h} * \mathrm{ng} / \mathrm{ml})$ & $2640.32 \pm 168.51$ & $3795.00 \pm 366.75$ & $\mid \mathrm{Z}$ obs $\mid=2.86>1.97(\mathrm{~S})$ \\
\hline C last $(\mathrm{ng} / \mathrm{ml})$ & $<\mathrm{LOQ}$ & $151.16 \pm 3.59$ & \\
\hline T $\max (\mathrm{h})$ & 3 & 3 & \\
\hline $\mathrm{t} 1 / 2(\mathrm{~h})$ & 3.57 & 10.39 & \\
\hline MRT $(\mathrm{h})$ & 5.84 & 15.84 & \\
\hline
\end{tabular}

Cmax, mean maximal concentrations compared by student test; AUC 0-16h, Area under the curve calculated by trapezoidal method from time 0 to time $16 \mathrm{~h}$ and compared by Bailer's method, Tmax, time to reach the maximal concentration; $C$ last, lowest measured concentration; $T$ 1/2, elimination half life time; MRT, Mean Residence Time ; NS, not significant.

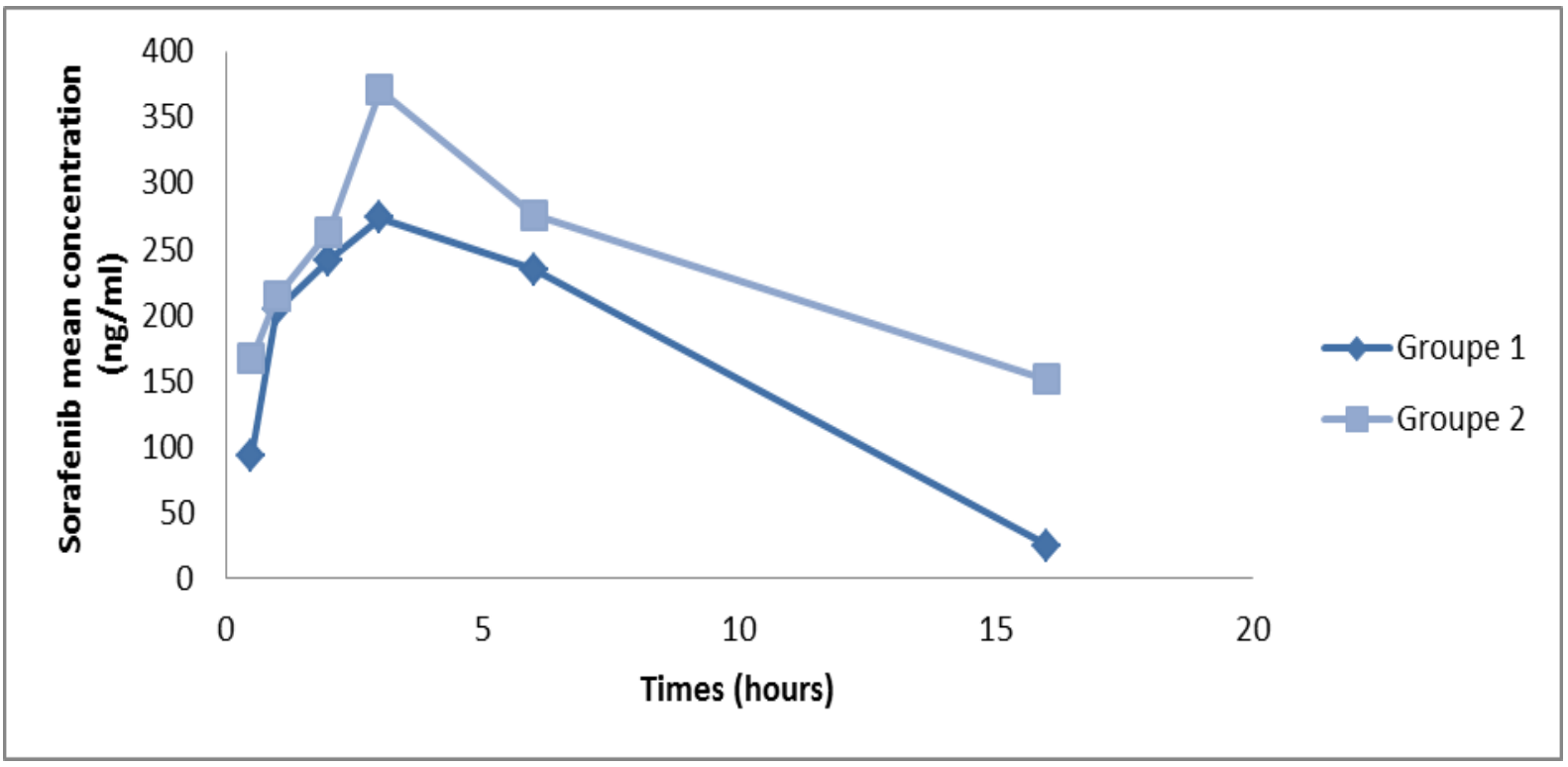

Groupe1: after oral administration of sorafenib $(5 \mathrm{mg} / \mathrm{kg})$

Groupe2: after oral administration of sorafenib $(5 \mathrm{mg} / \mathrm{kg})$ after pretreatement with bevacizumab $(5 \mathrm{mg} / \mathrm{kg})$

Figure 3: Mean plasma concentration-time curve of sorafenib in the absence and in the presence of bevacizumab.

\section{Discussion}

The efflux of anticancer drugs from tumor cells during treatment is one of the causes of treatment failure. The expression of P-gp in the small intestine, liver and kidneys may be responsible for changes in the pharmacokinetics of P-gp-mediated drugs and then for the failure of treatment ${ }^{[19]}$. To avoid this, several P-gp inhibitors have been tested, but their use is not approved in clinical practice because of drug interactions and side effects ${ }^{[20]}$.

In vitro, we observed in IGROV1-DXR cancer cells, a significant increase in the intracellular accumulation of doxorubicin in a dose dependent manner after pretreatment with bevacizumab or sorafenib. This indicates that resistance to doxorubicin was attenuated by pretreatment with either drug, due to their modulating effect of the functionality of P-gp, an efflux pump for doxorubicin. A similar effect was observed with verapamil (a known P-gp inhibitor and positive control of our test). Bevacizumab could directly interact with P-gp and modulate its functionality.

Huang et al. have shown that expression of MDR1 was significantly decreased after sorafenib treatment in a human gastric cancer cell line SGC7901/DDP and may reverses resistance to cisplatin through down-regulating MDR1 expression ${ }^{[21]}$.

Wei L.et al have explored the role of sorafenib in reversing MDR in hepatoma cells and have equally showed that sorafenib partially reversed the drug resistance of BEL-7402/FU cells to adriamycin $^{[22]}$. 
M.R. Bani et al. have also shown that exposure of ovarian adenocarcinoma tumor endothelial cells to sorafenib abrogates resistance to doxorubicin and paclitaxel in vitro, increasing drug accumulation with no beneficial effect to cytotoxic drugs that are not P-glycoprotein substrate ${ }^{[9]}$.

J. Dong et al. ${ }^{[8]}$ have shown that sorafenib exerts potent inhibitory activity against epithelial-mesenchymal transition (EMT) and multidrug resistance (MDR) by inhibiting mitogenactivated protein kinase (MAPK) signaling in HCC. However, after long-term exposure to sorafenib, HCC cells exhibit EMT and resistance to sorafenib.

A meta-analysis of four studies concluded that the addition of bevacizumab to chemotherapy offers meaningful improvement in progression-free survival (PFS) and objective response rate (ORR) in ovarian cancer treatment ${ }^{[23]}$.

Since sorafenib is a known substrate of P-gp, we suspected that bevacizumab could increase its concentration in vivo.

In our work we performed a pharmacokinetic study of sorafenib after oral administration, with or without pretreatment by bevacizumab, in plasma of mice bearing a human colorectal cancer xenograft and compared the results of both groups. Tmax was 3 hours in both groups (pre-treated or not by bevacizumab), similar to Tmax reported in PK studies in mice ${ }^{[24,25]}$. We observed a nonsignificant increase in $\mathrm{Cmax}$ in the pretreated group with bevacizumab, but a significant increase in sorafenib AUC in plasma. The half-life and MRT were higher in the pretreated group with bevacizumab. These results indicate that pretreatment with bevacizumab increases plasma concentrations and exposure to the drug.

The increase of Cmax indicates an effect on the intestinal absorption of sorafenib, the variation of which is not significant, probably due to the high bioavailability of sorafenib which could reach $80 \%$ in mice. The elimination of sorafenib is mainly biliary. In fact, the increase in the half-life of sorafenib and the MRT are signs of decreased elimination, probably due to inhibition elimination bile duct of P-gp ${ }^{[25]}$.

\section{Conclusion}

Bevacizumab and sorafenib, two anti-angiogenic drugs could sensitize tumor cells to chemotherapies by decreasing $\mathrm{P}$ glycoprotein functionalities like we shown in vitro with a beneficial effect when these drugs are combined.

Inhibition of P-glycoprotein functionality by bevacizumab could restore thus chemosensibility and increase plasma concentration of sorafenib, probably due to a P-glycoprotein pharmacological dependent interaction.

The anti-angiogenic activity of these two drugs might also be potentiated by the modulation of P-glycoprotein functionalities that could sensitize tumor endothelial cells to cytotoxic agents.

\section{Acknowledgement}

We thank the Cremec consortium that permitted the establishment of the xenograft model CR-IGR016P ('projet C.Re.M.E.C.') and Dr Simone Orbach for her kind help.

\section{Compliance with Ethical Standards}

The experimental protocol was approved by the Local Animal Experimentation Committee $\left(\mathrm{N}^{\circ} 26\right.$, Ministère de la Recherche et de l'Enseignement Supérieur).

\section{Conflict of Interest}

The authors declare no conflict of interest.

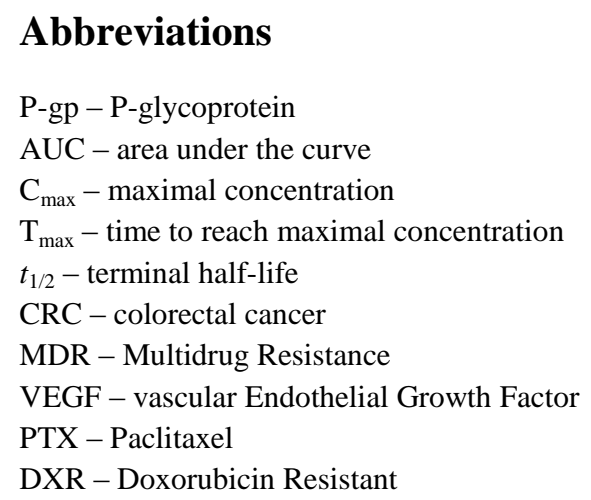

\section{References}

[1] Llovet J, Ricci S, Mazzaferro V, Hilgard P, Raoul J, Zeuzen $\mathrm{S}$ et al. Sorafenib improves survival in advanced hepatocellular carcinoma, (HCC): results of a phase III randomized placebo-controlled trial (SHARP trial). J Clin Oncol. 2007; 18S (25).

[2] European Medicines Agency (EMEA), NEXAVAR: EPAR - Scientific Discussion, 2007, [Internet], Available from:

http://www.ema.europa.eu/docs/en_GB/document_librar y/EPAR_-

_Scientific_Discussion/human/000690/WC500027707.p df [Consulted 12 May 2015].

[3] Monograph of sorafenib. VIDAL Ed. 2017.

[4] Pascaline Boudou-Rouquetre, Stanislas Ropert, Olivier Mir, Romain Coriat, Bertrand Billemont, Michel Tod, et al. Variability of Sorafénib Toxicity and Exposure over Time: A Pharmacokinetic/Pharmacodynamic Analysis. The Oncologist Express. 2012; 17:1204-1212.

[5] Gao B, Yeap S, Clements A, Balakrishnar B, Wong M, Gurney H. Evidence for therapeutic drug monitoring of targeted anticancer therapies. J Clin Oncol. 2012 Nov 10; 30(32): 4017-25.

[6] Di Marco V, De Vita F, Koskinas J, Semela D, Toniutto P, Verslype C. Sorafenib: from literature to clinical practice. Ann Oncol. 2013 Apr; 24 Suppl 2:ii30-ii37.

[7] Jurjen S. Lagas, Robert A.B. van Waterschoot, Rolf W. Sparidans, Jos H. Beijnen and Alfred H. Schinkel. Breast Cancer Resistance Protein and P-glycoprotein Limit Sorafenib Brain Accumulation. Mol Cancer Ther February 2010 9; 319-326.

[8] Dong J, Zhai B, Sun W, Hu F, Cheng H, Xu J Activation of phosphatidylinositol 3- kinase/AKT/snail signaling pathway contributes to epithelial-mesenchymal transition-induced multi- drug resistance to sorafenib in hepatocellular carcinoma cells. PLoS ONE. 2017; 12(9): e0185088.

[9] Maria Rosa Bani ; Alessandra Decio; Raffaella Giavazzi; Carmen Ghilardi.. Contribution of tumor endothelial cells to drug resistance: anti-angiogenic tyrosine kinase inhibitors act as p-glycoprotein antagonists Angiogenesis (2017) 20:233-241DOI 10.1007/s10456-017-9549-6

[10] Ambudkar SV, Dey S, Hrycyna CA et al. Biochemical, cellular, and pharmacological aspects of the multidrug transporter. Annu Rev Pharmacol Toxicol. 1999; 39:361-398. doi:10.1146/ annurev.pharmtox.39.1.361.

[11] Hyun Joo Jang, Bum Jun Kim, Jung Han Kim, Hyeong $\mathrm{Su}$ Kim. The addition of bevacizumab in the first-line 
treatment for metastatic colorectal cancer: an updated meta-analysis of randomized trials. Oncotarget, 2017, Vol. 8, (No. 42), pp: 73009-73016.

[12] E. Galanis, K. A. Jaeckle, S. Anderson, T. J. Kaufmann, J. H. Uhm, C. Giannini...Show More. NCCTG phase II trial of bevacizumab in combination with sorafenib in recurrent GBM. Journal of clinical oncology: 2018 (May) Vol. 28, no. 15_suppl.

[13] Joleen M. Hubbard, George Kim, Mitesh J. Borad, Elizabeth Johnson, Rui Qin, Janet Lensing, Suneetha Puttabassavaiah, John Wright, Charles Erlichman and Axel Grothey.Phase I trial of FOLFIRI in combinaison with sorafenib and bevacizumab in patients with advanced gastrointestinal malignicies.Invest New Drugs. 2016 February; 34(1): 96-103.

[14] Philippe V, Zahel T, Bärtl K, Rasch S, Ebert O, Schmid RM, Rummeny E, Algül H. Influence of Sorafenib and Bevacizumab on pancreatic volume - A monocentric CT based analysis. Pancreatology.2016 jul-Aug; 16(4):621624.

[15] Alliance for clinical trials in oncology. Sorafenib and bevacizumab in treating patients with metastatic colorectal cancer. Clinicaltrials.gouv. august 2017.

[16] Bénard J., Da Silva J., De Blois MC. et al. 1985. Characterization of a human ovarian adenocarcinoma line, IGROV1, in tissue culture and in nude mice. Cancer Res. 45, 4970-4979.

[17] Jovelet C. Bénard J, Forestier F et al. 2012. Inhibition of $\mathrm{P}$-glycoprotein functionnality by vandetanib may reverse cancer cell resistance to doxorubicin. Eur. J. Pharm. Sci. 46(5), 484-491.
[18] Bailer AJ. Testing for the equality of area under the curves when using destructive measurement techniques. J Pharmacokinet Pharmacodyn. (1988) 16 303-309.

[19] Schinkel AH, Mayer U, Wagenaar E, Mol CA, van Deemter L, Smit JJ, et al. Normal viability and altered pharmacokinetics in mice lacking mdr1-type (drugtransporting) P-glycoproteins. Proc Natl Acad Sci U S A. 1997 Apr 15; 94(8):4028-33.

[20] Yu M, Ocana A, Tannock IF. Reversal of ATP-binding cassette drug transporter activity to modulate chemoresistance: why has it failed to provide clinical benefit? Cancer Metastasis Rev. 2013 Jun;32(1-2):21127.

[21] Huang YS, Xue Z, Zhang H. Sorafenib reverses resistance of gastric cancer to treatment by cisplatin through down-regulating MDR1 expression. Med Oncol. 2015 Feb; 32(2):470 doi: 10.1007/s12032-014-0470-1.

[22] Wei L, Huang N, Yang 1 et al. Sorafenib reverses multidrug resistance of hepatoma cells in vitro. Nan Fang Yi Ke Da Xue Xue Bao. 2009 May; 29(5):1016-9, 1023.

[23] Ye Q, Chen H-L: Bevacizumab in the treatment of ovarian cancer: a meta-analysis from four phases III randomized controlled trials. Arch Gynecol Obstet 2013, 288:655-666.

[24] Pawaskar DK, Straubinger RM, Fetterly GJ, Hylander BH, Repasky EA, Ma WW, et al. Physiologically based pharmacokinetic models for everolimus and sorafenib in mice. Cancer Chemother Pharmacol. 2013 May;71(5):1219-29.

[25] Saber-Mahloogi HM, DE. . Pharmacology reviewSorafenib. Center for Drug Evaluation and Research; Rockville- FDA. 2005. NDA 21,923. 